\title{
Pacientes com traqueostomia: conhecimentos, atitudes e práticas das equipes do serviço de atenção domiciliar
}

\author{
Luiz Antônio da Silva Teixeira \\ Graduado em História pela Universidade Federal do Rio de Janeiro, Mestre em Saúde Coletiva pela Universidade do Estado \\ do Rio de Janeiro e Doutor em História Social pela Universidade de São Paulo \\ Faz parte da equipe da Casa de Oswaldo Cruz (Fiocruz), trabalha no Departamento de Pesquisa e Professor colaborador no \\ Programa de Pós-graduação em História das Ciências e da Saúde \\ 凶luiztei3@gmail.com \\ Mônica Cristina da Silva Castro \\ Graduada em Licenciatura Plena e Bacharel em Enfermagem pela Universidade Federal do Amapá \\ Especialista em Unidade de Terapia Intensiva. Mestre em Saúde da Família \\ Docente na Faculdade Estácio de Macapá, no Curso de Enfermagem \\ $凶$ monica.cristinacastro@hotmail.com
}

Recebido em 15 de fevereiro de 2019

Aceito em 3 de setembro de 2019

\begin{abstract}
Resumo:
O Programa Melhor em Casa é constituído pelas equipes do Serviço de Atenção Domiciliar inseridas em área territorial adscrita. Tem por objetivo melhorar e ampliar a assistência no SUS a pacientes com agravos de saúde, que possam receber atendimento humanizado, em casa, perto da família. Assim, a pesquisa teve por objetivo, identificar os conhecimentos, atitudes e práticas das equipes que compõe o serviço de atenção domiciliar, em relação ao processo de atenção à saúde dos pacientes com traqueostomia, internados no domicílio, no município de Macapá. Trata-se de um estudo descritivo, com abordagem qualitativa, realizado com dezessete profissionais que atuam no Serviço de Atenção Domiciliar. Os dados foram coletados por meio de entrevista semi-estruturada com uso de um roteiro e analisados através da técnica de análise de conteúdo proposta por Bardin. Utilizou-se também a análise de documentos oficiais e observação sistemática que possibilitou descrever os aspectos relacionados à dinâmica do serviço e das equipes. O estudo revelou que a estrutura disponível para a realização da atenção domiciliar é um ponto crítico e desfavorável comparado ao arcabouço teórico que o programa preconiza. Foi possível considerar o Melhor em Casa como um programa tronco, conectado com os demais programas assistenciais existentes dentro da oferta de serviços da atenção primária de saúde. Concluiu-se que o modelo de assistência que se propõe o programa coloca-se a favor de uma de assistência integral ao indivíduo, sendo de extrema importância a disponibilização de condições mínimas necessárias para a execução das práticas que ultrapassem o modelo tradicional de assistência à saúde.
\end{abstract}

Palavras-chave: Assistência domiciliar, Traqueostomia, Processo de trabalho, Atenção primária à saúde. 


\title{
Tracheostomy patients: knowledge, attitudes and practices of home care teams
}

\begin{abstract}
:
The "Melhor em Casa" Program is made up of the Home Care Service teams inserted in the assigned territorial area. Its objective is to improve and expand SUS assistance to patients with health problems who can receive humanized care at home, near their families. Thus, the research aimed to identify the knowledge, attitudes and practices of the teams that make up the home care service, in relation to the health care process of tracheostomy patients, hospitalized at home, in the city of Macapá. This is a descriptive study with a qualitative approach, conducted with seventeen professionals who work in the Home Care Service. Data were collected through semi-structured interviews using a script and analyzed using the content analysis technique proposed by Bardin. It was also used the analysis of official documents and systematic observation that allowed to describe the aspects related to the dynamics of the service and the teams. The study revealed that the structure available for home care is a critical and unfavorable point compared to the theoretical framework that the program advocates. It was possible to consider the Best at Home as a trunk program, connected with the other existing assistance programs within the provision of primary health care services. It was concluded that the model of care proposed by the program is in favor of comprehensive care to the individual, being extremely important to provide minimum conditions necessary for the implementation of practices that go beyond the traditional model of health care.
\end{abstract}

Keywords: Home care, Tracheostomy, Work process, Primary health care.

\section{Pacientes com traqueotomía: conocimiento, actitudes y prácticas de los equipos de atención domiciliaria}

\section{Resumen:}

El programa "Melhor em Casa" está compuesto por los equipos del Servicio de Atención Domiciliaria insertados en el área territorial asignada. Su objetivo es mejorar y expandir la atención del SUS a pacientes con problemas de salud que pueden recibir atención humanizada en el hogar, cerca de sus familias. Por lo tanto, la investigación tuvo como objetivo identificar el conocimiento, las actitudes y las prácticas de los equipos que conforman el servicio de atención domiciliaria, en relación con el proceso de atención médica de pacientes traqueostomizados, hospitalizados en casa, en la ciudad de Macapá. Este es un estudio descriptivo con un enfoque cualitativo, realizado con diecisiete profesionales que trabajan en el Servicio de Atención Domiciliaria. Los datos se recopilaron mediante entrevistas semiestructuradas utilizando un guión y se analizaron utilizando la técnica de análisis de contenido propuesta por Bardin. También se utilizó el análisis de documentos oficiales y la observación sistemática que permitió describir los aspectos relacionados con la dinámica del servicio y los equipos. El estudio reveló que la estructura disponible para el cuidado en el hogar es un punto crítico y desfavorable en comparación con el marco teórico que defiende el programa. Fue posible considerar el programa Best at Home como un programa troncal, conectado con otros programas de asistencia existentes dentro de la provisión de servicios de atención primaria de salud. Se concluyó que el modelo de atención propuesto por el programa está a favor de la atención integral al individuo, siendo extremadamente importante proporcionar las condiciones mínimas necesarias para la implementación de prácticas que van más allá del modelo tradicional de atención médica.

Palabras-clave: Cuidados en el hogar, Traqueotomía Proceso de trabajo, Atención primaria de salud. 


\section{INTRODUÇÃo}

A atenção domiciliar é atualmente pauta de destaque no contexto da saúde pública, uma vez que incorpora a abordagem integral do indivíduo e se caracteriza como um instrumento de intervenção importante no âmbito da atenção primária à saúde. Sua análise relacionada ao paciente com traqueostomia, internado no domicílio, é o tema da presente pesquisa.

O Programa de Internação Domiciliar teve início no Brasil, em abril de 2002, sancionado, pelo Ministério da Saúde, através da Lei nº 10.424 que estabeleceu, no âmbito do Sistema Único de Saúde (SUS), o cuidado domiciliar como modalidade de assistência em saúde. A Lei incluiu, principalmente, “os procedimentos médicos, de enfermagem, fisioterapêuticos, psicológicos e de assistência social, necessários ao cuidado integral dos usuários em seu domicílio”. (BRASIL, 2002, p. 1)

Através do lançamento do Programa Melhor em Casa pelo Governo Federal em 2011, instituído pela Portaria 2.029, de 24 de agosto de 2011, foram garantidos aos municípios com menor porte populacional a implantação em seus territórios os serviços de atenção domiciliar com o apoio do Ministério da Saúde. (BRASIL, 2011). O programa tem como objetivo "cuidar dos pacientes no domicílio, ajudar a fazer a gestão do cuidado dos mesmos e realizar a articulação dos pontos de atenção de modo a ampliar a resolutividade do cuidado". (Idem, 2011). Para suporte e complementação das ações de saúde a Portaria 825/2016 estabelece a criação das Equipes Multiprofissionais de Atenção Domiciliar (EMAD) e Equipes Multiprofissionais de Apoio (EMAP), ambas vinculadas ao Serviço de Atenção Domiciliar (SAD).

A atenção domiciliar encontra-se inserida na atenção primária à saúde através das equipes de Estratégia Saúde da Família (ESF) das Unidades Básicas de Saúde (UBS) adscritas ao território e pelas equipes do Serviço de Atenção Domiciliar (SAD). Mendes (2015) complementa que na Atenção Primária à Saúde (APS) existe uma expressiva demanda de cuidados domiciliares para as equipes de saúde, especialmente para os agentes comunitários de saúde.

Na cidade de Macapá, estado do Amapá, o Serviço de Atendimento Domiciliar foi implantado no Hospital de Clínicas Dr.o Alberto Lima (HCAL) no dia 11 de agosto de 2004, com o objetivo de planejar o processo de desospitalização e a alta para o domicílio, 
proporcionando aos pacientes a articulação e a integração com a rede de saúde do território, obedecendo os critérios de elegibilidade do Programa Melhor em Casa.

Com o processo de expansão do Programa Melhor em Casa, e particularmente no município de Macapá, espaço deste estudo, faz-se necessário mencionar que em 13 de abril de 2012, o governo do estado lançou a Resolução n.o 015/12 - CIB/AP, na qual aprovou o projeto de implantação do Serviço de Atenção Domiciliar, compondo 03 (três) equipes multiprofissionais de atenção domiciliar e 02 (duas) equipes multiprofissionais de apoio, sob a gestão da secretaria municipal de saúde e 01 (uma) equipe multiprofissional de atenção domiciliar sob coordenação da gestão estadual (AMAPÁ, 2012)

Com o processo de implantação do SAD na região de Macapá a fim de reorganizar os serviços, realizar a desospitalização, reduzir os custos de internações hospitalares, é possível aos portadores de cânula de traqueostomia internados no domicílio, a prestação de cuidados por equipes multiprofissionais.

O interesse nessa área de estudo foi despertado a partir da atuação como Enfermeira e Docente nos serviços de atenção às urgências e emergências na área hospitalar, no Serviço de Atendimento Móvel de Urgência (SAMU 192) e no campo de estágio em saúde coletiva, ao observar e realizar cuidados de enfermagem aos pacientes com traqueostomia.

À isso associou-se a inquietação em investigar o acompanhamento desses pacientes na rede de atenção primária pelas Equipes Multiprofissionais de Atenção Domiciliar no município de Macapá, uma vez que os atendimentos realizados no âmbito pré-hospitalar, remonta a curiosidade de investigar o processo de trabalho do SAD e as interfaces que permeiam esses profissionais, identificar se há barreiras e dificuldades enfrentadas pelas equipes de saúde. Fatores como os mencionados pareciam-me importantes para o conhecimento dos problemas quanto a atenção à saúde dos pacientes com traqueostomia.

No que tange a relevância acadêmica, esse trabalho justifica-se pelo fato de no estado do Amapá existirem poucos estudos que discutem esse contexto, por ser um tema pouco explorado e por investigar um assunto recente de um Programa do Governo Federal (Melhor em Casa) lançado no ano de 2011, uma vez que os pacientes com traqueostomia podem ser encontrados em dois cenários distintos: no ambiente hospitalar ou internado no domicílio.

Salienta-se a importância social da pesquisa, pois o paciente com traqueostomia no contexto domiciliar, possui limitações quanto ao manejo do dispositivo, dúvidas dos 
familiares/cuidadores quanto aos cuidados básicos de higiene e como devem proceder em situações de emergência, se afastam do convívio da comunidade, do trabalho, provisoriamente ou definitivamente, dependendo do grau de cronicidade do agravo que o levou ao uso da traqueostomia.

Este estudo contribuirá para novas pesquisas e para o apoio aos inúmeros profissionais que atuam não somente no Serviço de Atenção Domiciliar, mas na rede que integra o Sistema Único de Saúde. O estudo pode contribuir ainda na concepção das políticas públicas de saúde, uma vez que poderão ser detectadas potencialidades e fragilidades entre as equipes que compõe o SAD, cabendo assim reflexões críticas e construtivas ao Programa Melhor em Casa e recomendações para os gestores locais de saúde do município.

Nesse sentido, o estudo tem como questões norteadoras as seguintes indagações: Como se organiza o processo de cuidados domiciliares à saúde do paciente com traqueostomia no município de Macapá? De que maneiras são aplicados os conhecimentos, atitudes e práticas dos profissionais envolvidos no Serviço de Atenção Domiciliar e como estes se relacionam com os resultados no campo de trabalho? Como é realizado o itinerário terapêutico desses pacientes em situações clínicas de urgência e emergência?

Diante das questões apresentadas a presente pesquisa teve como objetivo identificar os conhecimentos, atitudes e práticas das equipes que compõe o Serviço de Atenção Domiciliar, em relação ao processo de atenção à saúde dos pacientes com traqueostomia, internados no domicílio, no município de Macapá.

\section{METODOLOGIA}

Trata-se de um estudo descritivo, com abordagem qualitativa, realizado com 17 profissionais que atuam no Serviço de Atenção Domiciliar do município de Macapá, sendo um Médico, três Enfermeiros, cinco Técnicos de Enfermagem, três Fisioterapeutas, dois Fonoaudiólogas, um Nutricionista, um Psicólogo e um Assistente Social.

Como critérios de inclusão e de exclusão para a participação na pesquisa, foi necessário que os profissionais do Serviço de Atenção Domiciliar pertencessem ao quadro de servidores da Secretaria Municipal de Saúde de Macapá, independente do regime de contratação, de ambos os sexos, que atuassem no mínimo seis meses no programa (devido ao 
tempo de experiência no serviço) e assinassem o Termo de Consentimento Livre e Esclarecido (TCLE). Foram excluídos 04 profissionais que encontravam-se de férias e/ou de licença em modo geral.

Os dados foram coletados por meio de entrevista semi-estruturada com uso de um roteiro e analisados através da técnica de análise de conteúdo proposta por Bardin (2009, p.90), na qual tem por objetivo "poder inferir algo, através de palavras, a propósito de uma realidade [...] representativa de uma população de indivíduos".

Utilizou-se também a análise de documentos oficiais - analisado apenas o Plano Municipal de Saúde do município (quadriênio 2014-2017), documento oficial oriundo da Secretaria Municipal de Saúde de Macapá, quanto ao relatório anual de gestão do município, exercício 2012 a 2014, por questões administrativas, não foi possível sua análise.

E por fim, utilizou-se a técnica de observação sistemática, que possibilitou descrever os aspectos relacionados à dinâmica do serviço e das equipes para que se pudesse alcançar os objetivos pretendidos (GIL, 2008). Por essa razão elaborou-se previamente um roteiro de observação para descrever o funcionamento das unidades, o espaço físico, rotina diária e a dinâmica do serviço, através da tomada de notas por escrito.

As entrevistas foram registradas através de equipamento de gravação (áudio), com prévia autorização dos participantes, esclarecendo o caráter confidencial e o anonimato de suas respostas.

Foram identificados os principais aspectos destacados pelos profissionais do SAD acerca da atenção domiciliar, dos quais emergiram cinco categorias temáticas: Concepções dos profissionais de saúde acerca do Programa Melhor em Casa, o processo de trabalho na atenção domiciliar (desdobrada em duas subcategorias), as concepções das equipes do serviço de atenção domiciliar sobre a relação de trabalho com a estratégia saúde da família, os avanços, os limites e as perspectivas das equipes do serviço de atenção domiciliar em relação a atuação em campo e por fim referência e contrarreferência no Programa Melhor em Casa diante das demandas ou problemas de saúde dos pacientes com traqueostomia.

Quanto aos aspectos éticos, o presente estudo foi norteado pelas diretrizes e normas regulamentadoras dispostas na Resolução 466/12 do Conselho Nacional de Saúde, no que diz respeito à pesquisa envolvendo seres humanos. 0 sigilo dos dezessete participantes foi 
preservado, por meio da adoção de siglas para identificação das falas, a fim de manter a sua privacidade.

A sigla que forma o código utilizado nesse estudo foi a letra P, para garantir o sigilo e a privacidade dos sujeitos da pesquisa (Enfermeiro, Técnico de Enfermagem, Médico, Fisioterapeuta, Psicólogo, Assistente Social, Fonoaudiólogo e Nutricionista), seguidos de números, os quais auxiliaram na identificação das falas. Por exemplo, P-1, P-2, P3 e assim sucessivamente.

$O$ projeto do qual decorre este estudo obteve a aprovação através do Parecer Consubstanciado do Comitê de Ética e Pesquisa da Universidade Estácio de Sá, sob o CAAE n.ำ 49192515.0.0000.5284, número do Parecer: 1.389.189. A pesquisa também obteve autorização da Secretaria Municipal de Saúde de Macapá, através de uma carta de anuência.

\section{RESULTADOS}

A partir da análise e discussão dos dados, emergiram-se cinco categorias, descritas à seguir.

\section{Primeira Categoria: Concepções dos profissionais de saúde acerca do Programa Melhor em Casa}

Nessa categoria, foram identificados os aspectos relacionados às concepções das equipes do Serviço de Atenção Domiciliar do município de Macapá sobre o Programa, no qual houve a necessidade de subcategorizar os profissionais de saúde em três grupos: a primeira subcategoria refere-se àqueles profissionais que têm algum conhecimento sobre o Programa (que perfizeram $64,7 \%$ dos entrevistados); a segunda compõe-se dos que não tinham informações sobre ele e passaram a conhecer seus fundamentos e ações quando nele ingressaram (totalizaram 29,4\% dos entrevistados); e a terceira, formada pelos profissionais que, embora conheçam o Programa, não creem na factibilidade de suas ações (abrangência de 5,9\% dos entrevistados).

Com relação à primeira subcategoria apontada por este estudo, os depoimentos dos entrevistados evidenciam que os profissionais conhecem a fundamentação teórica do 
Programa Melhor em Casa, os critérios de admissibilidade neste, a importância e o envolvimento do cuidador no domicílio, assim como o serviço de atenção domiciliar.

O Programa e o SAD, visam atender os pacientes de alta complexidade. [...] É um programa do Governo Federal [...] É um programa novo, aqui no Estado, e ele veio pra tirar essa demanda do NASF, que é o Núcleo de Apoio à Saúde da Família. Então, é assim: geralmente, os pacientes de alta complexidade, eles são encaminhados pro EMAP, pro SAD, a médica faz uma avaliação para verificar se esse paciente, ele pode ser admitido, se ele é do perfil da equipe, e aí a equipe multidisciplinar faz a avaliação pra verificar a necessidade do acompanhamento ou não. (P-7).

Um outro grupo de profissionais não tinham informações sobre o Programa e passaram a conhecer seus fundamentos e ações quando nele ingressaram:

[...] Eu entrei [no] finalzinho de abril [2015] e, assim, sendo bem sincera, eu nem sabia da existência do programa. Fui conhecer, realmente, quando fui pegar minha carta de apresentação e a coordenadora [...], que me explicou como que funcionava, qual que seria mais ou menos a minha atuação aqui, e aí, quando cheguei aqui eu fui realmente conhecer como é que funcionava, como é que era [...].(P-1).

Outra análise relevante a se fazer tem relação com o grupo de profissionais, indicados no estudo, que embora conheçam os fundamentos teóricos do Programa, não creem na factibilidade de suas ações. Destaca-se:

Eu acho que ele tem uma teoria muito boa. Infelizmente, na prática não tem como se aplicar. Porque a intenção é tirar os pacientes graves dos hospitais pra ficar em casa, mas a gente precisa de estrutura, e a estrutura é o que nós não temos. Então, o pessoal [as equipes] tem muito boa vontade, acho que até que a teoria, como eu fale foi um mérito, a pessoa pensar nisso, mas falta suporte, falta mais equipamento, material, pra gente poder dar o melhor pro paciente, mesmo. (P-3). 


\section{Segunda Categoria: 0 processo de trabalho na atenção domiciliar e o paciente com traqueostomia}

Nesta categoria, serão apresentadas duas subcategorias, que enfatizam o processo de trabalho das EMAD's/EMAP's diante dos cuidados realizados ao paciente com traqueostomia, com ênfase nos instrumentos utilizados para a sua organização.

A primeira subcategoria aborda o planejamento das atividades diárias dos profissionais e estudos de casos; a segunda, engloba os tipos de tecnologias utilizadas pelas equipes do SAD.

Numa perspectiva Marxista (1996) podemos dizer que o trabalho é um processo em que o indivíduo por sua própria deliberação, media, regula e controla suas reações com a natureza. Contudo, é considerado simples e abstrato. Todo trabalho gera um produto, e este produto para ser gerado e consumido precisa de meios (instrumentos) e objetos (matériaprima). No entanto, o indivíduo tem a perspicácia de imaginar o resultado que espera alcançar antes mesmo de finalizar o trabalho, o que torna o seu trabalho não semelhante ao trabalho dos outros animais e aponta para sua capacidade de ação no mundo com potencial transformador das práticas sociais. (SANTOS, 2010)

Assim, o processo de trabalho pode ser entendido como um conjunto de saberes, instrumentos e meios, tendo, como sujeitos, profissionais que se organizam para produzirem serviços de modo a prestarem assistência individual e coletiva para obtenção de produtos e resultados decorrentes de sua prática (MENDES GONÇALVES, 1994).

$\mathrm{Na}$ atenção domiciliar, esse processo pode ser percebido ao vislumbrar o trabalho das equipes multiprofissionais diante do cuidado ao paciente com traqueostomia, onde cada profissional pode traçar estratégias com intervenções terapêuticas diferenciadas e de acordo com a necessidade de cada paciente na própria casa do indivíduo.

De acordo com Smeltzer \& Bare (2005, p. 646) "uma traqueostomia é um procedimento cirúrgico em que é feita uma abertura para dentro da traquéia". É inserido um tubo chamado cânula de traqueostomia, que serve como um atalho para levar o ar até os pulmões (ECHER et al., 2013, p. 6)

Para um melhor entendimento dos conceitos sobre alguns procedimentos invasivos que são utilizados nos pacientes, Matheus et al. (2004, p. 1) explicam que: 
Estoma, ostoma, estomia ou ostomia são palavras de origem grega que significam abertura ou boca, são designativos que indicam a exteriorização de uma víscera oca através do corpo. Sua denominação depende do local de onde provêm.

A traqueostomia é uma pequena abertura da traqueia com a finalidade de ventilar o ar para dentro dos pulmões (figura 1).

Figura 1. Traqueostomia

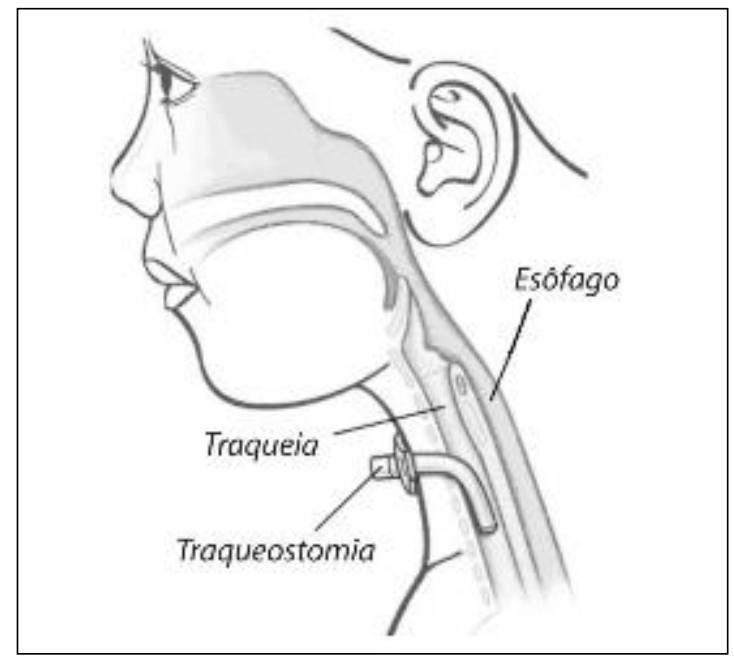

Fonte: Manual de orientações sobre Traqueostomia (ERCHER, 2013)

A traqueostomia é indicada para indivíduos com distúrbios respiratórios que necessitam de suporte ventilatório prolongado, pois respiram através de um tubo que éligado a um aparelho mecânico. Além das complicações respiratórias, indica-se o procedimento em pacientes que tiveram traumas, tumores na garganta, doenças neurológicas, malformações, etc. (ECHER et al., 2013). Ainda para os autores, a traqueostomia tem o objetivo de manter a via aérea aberta, garantindo a passagem do ar até os pulmões. Ela facilita a respiração, proporciona mais conforto e segurança e auxilia na recuperação.

Desse modo, apresenta-se a organização do processo de trabalho das equipes do SAD no município de Macapá. 


\section{Primeira subcategoria: Planejamento das atividades diárias dos profissionais e os estudos de casos}

A participação, no planejamento, de todos os profissionais envolvidos no Programa é reconhecida como importante, visto que planejar significa identificar problemas (atuais e futuros), fixar prioridades de intervenção para implementar soluções, determinar se estas estão dentro da capacidade de ação da equipe que a planeja, identificar os fatores que determinam o estado de coisas consideradas insatisfatórias, estabelecer os cursos de ação possíveis, determinar responsabilidade da execução das soluções propostas e definir os procedimentos de avaliação (anteriores e posteriores). (MOSSER e BEGUN, 2015)

Dos depoimentos dos entrevistados, obtêm-se:

[...] a nossa prática, a nossa dinâmica, a gente trabalha sempre em equipe, e a equipe na essência da palavra. Todo mundo participa com ideias, com fóruns [...] então nós temos um paciente de atendimento de segunda a sexta e todos os profissionais têm atendimento pra eles, ou seja, a parte de curativo, com o técnico de enfermagem, o fonoaudiólogo precisa ir para outro paciente e precisa levar um técnico de enfermagem para ajudar na abordagem com o paciente e se esse paciente estiver em condições de fazer o procedimento ele faz, e se ela observar que a pressão arterial está alta, se o paciente não está muito agitado, e aí esse atendimento, ele fica suspenso, é feito as orientações, e aí ela pula pra outro atendimento, pra outro paciente. (P-9)

O planejamento quem faz é o enfermeiro, mas aí quando dá fica um na sala e o outro vai para área dar auxílio ao enfermeiro, ao médico ao fonoaudiólogo, ao Fisioterapeuta; a gente verifica pressão arterial e realiza curativos. (P-2).

Foi possível identificar também no estudo, outros aspectos relacionados ao planejamento semanal das equipes e que parece sofre limitações por dois fatores: a insuficiência de transporte para o atendimento domiciliar por todos os membros multiprofissionais e a alta demanda de pacientes a serem atendidos, principalmente pelos fisioterapeutas, conforme as declarações a seguir:

[...] é um carro só pra levar a equipe inteira. Esse carro é da própria secretaria de saúde do município, exclusivo e disponível pra nossa equipe, todos os dias de segunda a sexta-feira nós temos um carro disponível para fazer esse trabalho. Só que o carro não é suficiente para levar todos de uma vez só [...]. (P-9)

“[...] geralmente o paciente vem pra gente, se organiza pelo menos pra atender o paciente duas vezes na semana. Então como a nossa demanda é grande, a gente ter que dar alta de um paciente pra entrar outro, e assim vai, a gente consegue atender 


\section{Pacientes com traqueostomia: conhecimentos, atitudes \\ e práticas das equipes do serviço de atenção domiciliar}

em média quatro pacientes por dia, porque atende praticamente a equipe toda. [...] estou com uma paciente com traqueostomia, a gente atende ela duas vezes na semana, terça e quinta-feira, no mínimo, é o que a gente pode fazer, explica pro paciente a situação, pra família [...] a gente deixa já agendado para o paciente aguardar prontinho, pra não atrasar." (P-4).

“[...] primeiro a gente faz uma agenda e agenda o paciente, segundo a necessidade do paciente, a gente visita de duas a três vezes na semana, orientando sempre a família, porque a família é fundamental pra esse tipo de paciente, tanto como o cuidador que vai ficar responsável [..."] (P-11)

Segundo criticam Mosser e Begun (2015), as administrações do setor saúde têm demonstrado desconhecer ou não dar importância a essa deficiência no atendimento público de saúde já que, em vez de promover a eficácia da oferta através da adoção de melhores mecanismos de gestão, de instauração de mecanismos que incentivem a melhoria na qualidade, na análise das necessidades, no planejamento do desenvolvimento de novos recursos com bases em razões epidemiológicas e, em última instância, no aumento de capacidade de resposta do sistema, sendo necessário o aumento da oferta, se limitam a manter o status quo, o que somente consegue piorar progressivamente a situação.

Sabe-se que a fisioterapia integra os serviços oferecidos pelo Programa Melhor em Casa, portanto suas ações não podem ser limitadas, como ocorre no Programa, conforme a fala dos entrevistados. Segundo Malagutti et al. (2012), as ações domiciliares da fisioterapia se destinam primordialmente no âmbito da atenção a pessoas com problemas respiratórios ou lesões neurovasculares. Neste sentido, Mosser e Begun (2015) afirmam que a incorporação dessa especialidade nos programas de atenção domiciliar leva a uma diminuição das hospitalizações e um menor tempo de permanência no hospital. Assim, o tipo de intervenção realizada parece justificar um maior desenvolvimento deste nível de saúde, favorecendo a interrelação entre os níveis de atenção.

Portanto, deve-se priorizar e incentivar a realização de práticas voltadas ao atendimento domiciliar, que favoreça ambos os lados: o essencial, que é a assistência integral ao indivíduo internado no domicilio, assim como as equipes multiprofissionais que precisam de suporte estratégico para o alcance e a execução de suas atividades em campo.

Diante dessa magnitude, destaca-se a organização do processo de trabalho das equipes do Serviço de Atenção Domiciliar. Sanna (2007) utilizou em seus estudos os conceitos de 
Gomes et al. (1997) ao caracterizar os componentes do processo de trabalho: objeto, agentes, instrumentos, finalidades, métodos e produtos.

Em relação ao objeto, o autor discute sobre aquilo que se é trabalhado, e que será transformado mediante a ação do ser humano. Na prática, apontada no estudo, as equipes do SAD identificam como objeto de trabalho a realização de estudos de casos, conforme os depoimentos a seguir:

\footnotetext{
"Fazemos estudos de casos dos pacientes, todo mês, temos um espaço onde a coordenadora do programa consegue uma sala, para as nossas reuniões, com todos os EMAD's, as três equipes. A gente consegue fazer essa aproximação." (P-1 2).

"Mensalmente, a gente faz estudos de casos, há uma reunião com a coordenação [...], cada mês é uma equipe [...] e a gente apresenta três casos, são três pacientes que a equipe escolhe pra apresentar e comentar, trocando experiência [..." $]$ (P-8).
}

A realização periódica de sessões de estudo, sobretudo as de estudo de caso de pacientes, representam uma ação de suma importância para o aperfeiçoamento de toda a equipe do Programa, desde que seja um processo planejado e sistemático de ensino e aprendizagem, voltado a propiciar a aquisição, escolha e manutenção de práticas saudáveis e evitar as práticas de risco. O objetivo principal de tais sessões de estudo é a busca de conhecimentos, atitudes e comportamentos dos indivíduos integrantes da equipe, no sentido de uma saúde positiva (McEWEN; WILLS, 2009).

Portanto, ao lidar com os pacientes com traqueostomia no domicílio, é de extrema relevância a consolidação de um planejamento onde toda a equipe tenha participação, com ideias, sugestões, intervenções e avaliações, através do diálogo mútuo, em espaços para troca de experiências e realização de estudos de casos, inserindo a opinião do paciente ou familiares no planejamento da assistência à saúde.

Ressalta-se também a importância da sobrecarga de atividades para os membros da equipe, como um fator limitador, podendo haver uma interferência nos cuidados prestados ao indivíduo, comprometendo a sua qualidade de vida. Pondera-se ainda as questões administrativas relacionadas ao transporte e deslocamento das EMAD's/EMAP's, a qual pode ser sanada em consonância com a gestão local. 


\section{Segunda subcategoria: Tecnologias utilizadas pelas equipes do Serviço de Atenção Domiciliar}

Segundo o Scottini (2009, p. 320) a tecnologia "é a ciência que estuda as técnicas de trabalho; uso de conhecimentos científicos".

Como instrumento de trabalho no âmbito da saúde, as tecnologias podem ser classificadas em leve, leve-dura e dura. As tecnologias leves são aquelas utilizadas para agregar a relação entre o profissional de saúde e o usuário, na construção de vínculos através da confiança, do interesse e no ato de ouvir, no intuito de prestar o cuidado ao indivíduo. As leve-duras, retratam os saberes profissionais estruturados nas áreas especializadas, tais como a clínica médica, a psicanalítica, etc. Já as tecnologias duras, reportam a utilização de equipamentos, máquinas, normas e estruturas organizacionais (MERHY e FEUERWERKER, 2013; MARQUES e LIMA, 2004).

Um bom exemplo de tecnologia leve, voltada à atenção domiciliar, é a relação desenvolvida no domicílio, onde o vínculo, a autonomia e o acolhimento podem ser construídos através da relação entre o profissional e o usuário (MERHY, 2002).

Entretanto, ficou evidente durante a realização das entrevistas que as equipes de EMAD/EMAP preocupam-se com a utilização de tecnologias duras, enfatizando os materiais, equipamentos e insumos necessários para a realização do trabalho, deixando de considerar as demais tecnologias conforme é destacado:

"Parte desse material nós temos, tipo assim, material de insumo, os equipamentos básicos nós temos. Existem materiais que é de dispensação, por exemplo, os de alta complexidade [...] cateter de oxigênio, [...] sonda nasogástrica, sonda vesical de demora, oxigênio, bala de oxigênio [...] Aí já se torna mais difícil, mas nós solicitamos à coordenadora." (P-9).

"A gente tem [equipamentos]. E quando falta, a gente se vira, vai a uma outra unidade [UBS], pede daqui, pede dali, dá um jeito, sempre dá um jeito. Aspirador portátil, para aspirar um paciente, já foi feito o pedido, mas não foi ainda... [atendido]. No caso só tem esse paciente aí [traqueostomizado], ela [cuidadora] mesma faz [aspiração], [...] A gente até já solicitou à coordenadora [o equipamento], pra gente ter pra emergência, mas ainda não foi [disponibilizado]" (P-10)

“No caso [..], eu não tenho [equipamentos]... a única arma que eu tenho [...] é só a mão..." (P-4).

“[...] geralmente a família do paciente providencia, a gente mesmo não tem equipamentos, quando a família pode, ela vai e compra o aparelho, como o aspirador, a maioria dos nossos pacientes tem o aerossol em casa, a própria família consegue providenciar. Temos uma paciente que está saindo do suporte de oxigênio, 
de vez em quando com dispneia, cansando, aí a família vai e coloca o oxigênio nela, ela já está quase saindo."(P-12)

Primeiro é importante reconhecer que a falta de equipamentos básicos para o atendimento dos pacientes parece ser a característica mais marcante, apresentada pelo estudo. E esse é um dado negativo, pois muitos procedimentos em saúde prescindem de determinados insumos, equipamentos e tecnologias.

Isso remete ao que afirmam Mosser e Begun (2015), que, devido ao acúmulo do conhecimento e dos avanços tecnológicos ocorridos no setor da saúde, a assistência médica tem mudado profundamente nos últimos anos. Isso se deve, principalmente, ao impressionante desenvolvimento da tecnologia médica. O surgimento de algumas, impossíveis de se imaginar há algumas décadas, têm produzido mudanças muito significativas na configuração dos serviços de saúde.

Malagutti et al. (2012) reforçam que novas tecnologias médicas de inquestionável eficácia diagnóstica ou terapêutica se incorporam progressivamente aos serviços assistenciais. Entretanto, conforme é possível perceber nas falas dos entrevistados, os profissionais possuem fragilidades em relação à utilização dessas tecnologias, visto que nenhum deles abordou a utilização da tecnologia leve ou leve-dura.

Dessa forma, o aspecto relacionado ao estabelecimento do vínculo, que vai muito além do uso de máquinas, instrumentais e insumos, estabelecido através da escuta e a comunicação, pode ser um fator a ser repensado e organizado pelas equipes que atuam no SAD municipal, para que o processo do cuidado seja de fato bem sucedido.

Além disso, ao analisar o Plano Municipal de Saúde (quadriênio 2014-2017), percebese que existe a preocupação da gestão em garantir a melhoria da infraestrutura do setor saúde, com investimentos em equipamentos e materiais permanentes para as unidades básicas. No entanto, nos depoimentos apresentados essa ainda não é uma realidade alcançada.

Terceira Categoria: As concepções sobre o serviço e a relação de trabalho com a Estratégia Saúde da Família

A atenção básica se constituiu como o primeiro contato dos indivíduos com o sistema de saúde, tendo como alicerces os princípios da universalidade, acessibilidade (ao sistema), 
continuidade, integralidade, responsabilização, humanização, vínculo, equidade e participação social (BRASIL, 2012).

Associado ao Programa Estratégia Saúde da Família, o Melhor em Casa, também se utiliza dos princípios da territorialização, onde a atenção domiciliar faz parte do processo de trabalho das equipes, no qual é necessário a identificação dos usuários que serão contemplados dessa modalidade de atenção, para que na organização dos serviços sejam agregadas às tecnologias essenciais para a realização dos cuidados no âmbito domiciliar (BRASIL, 2012).

Os participantes revelaram sobre concepções acerca da relação de trabalho com a ESF:

Antes [nosso contato], era muito no boca a boca, realmente. Agora, de uns tempos prá cá, ta começando a se colocar em prática a questão das fichas. Então, se eles um paciente, que eles acham que é pra gente, eles preenchem a ficha. Alguns enfermeiros do PSF, a gente já entrou em contato, já explicou isso pra eles, que caso eles tenham algum paciente, eles preencham a ficha, tudinho, e entreguem aqui, pra gente. Aí, a gente pega essa ficha, marca uma avaliação com o paciente, pra saber se realmente é pra gente ou não. Se for prá gente, a gente admite [o paciente], se não, aí pega a ficha e devolve prá eles. (P-1).

"Eles [profissionais do PSF] vêm passar o caso aqui pra gente, tem o dia do [...] agente comunitário de saúde vir aqui [na UBS], e a gente ir na casa do paciente, a ACS foi levar a gente no endereço [do paciente]. A gente tem, sim, essa abertura." (P-3).

"O contato mais direto é com a Enfermeira, de todos da equipe, os enfermeiros, normalmente, ou o fisioterapeuta do ESF ou do NASF ligam pra ela. [...] Mas, pelo que a gente percebe, é um bom relacionamento sim, tem uma boa relação." (P-13).

"Como eu te disse antes, era no boca a boca, e a gente ficava perdido, porque vinha os profissionais de lá [ESF], diziam as coisas pra gente e não tinha nada documentado. E aí, a partir do momento que foi sentado com a [coordenação do programa] e foi solicitado pela equipe que houvesse essa parte documental, o que aconteceu: a gente recebe, sim [o paciente que vem encaminhado do PSF], desde que eles façam toda a triagem, preencha a documentação e nos entregue. E se o paciente não for nosso, a gente reencaminha pro PSF. O que é que acontece: infelizmente, a gente sabe "ah, precisa... é cadeirante, ah, é do EMAD"; "ah, é amputado, é do EMAD". $\mathrm{E}$, às vezes, a pessoa é cadeirante, mas ela tem autonomia, ela levanta da cadeira, ela faz tudo sozinho... Não é EMAD." (P-5).

Percebeu-se, a partir das falas dos informantes, que as tímidas medidas de integração do SAD e a Estratégia Saúde da Família foram de iniciativa dos membros das equipes domiciliares, em razão das dificuldades para a oferta de um serviço mais ágil ao paciente, e não por iniciativa das coordenações dos programas. 
Assis et al. (2010) julgam ser importante a integração dos serviços entre programas, tanto para os prestadores da atenção da saúde como para os pacientes. As políticas para a integração dos serviços deveriam incluir aspectos da integração clínica (relacionados com os benefícios para os pacientes) e aspectos organizativos (relacionados com a melhoria das condições de trabalho para os profissionais da atenção da saúde).

Apesar de que o conceito de integração faz parte de programas de políticas voltadas para assegurar o acesso da população aos serviços básicos de saúde, a exemplo do SAD e da ESF, o que se percebe é que, na prática, os sistemas de saúde não têm a capacidade para elaborar processos e estratégias de integração, com todos os aportes requeridos para tal e proporcionar o apoio aos dirigentes locais desses programas, especialmente nas regiões de escassos recursos e no contexto de sistemas de saúde descentralizados (GIOVANELLA, 2012).

Acredita-se que possa haver uma relação com a integração do SAD e a Estratégia Saúde da Família, no que tange aos desafios e superações apontados no estudo, uma vez que é perceptível a articulação ainda incipiente entre as equipes da atenção primária, principalmente quando se trata da admissibilidade dos pacientes no Programa Melhor em Casa e o papel das ESF's nesse contexto.

Malagutti et al. (2012) ressaltam a importância de se promoverem avaliações da eficácia da integração entre a Estratégia Saúde da Família e os demais programas. Sempre que for possível, tais avaliações devem ser planejadas para medir quatro dimensões principais: efetividade (benefícios medidos pelas melhorias na saúde), eficiência (relacionada com o custo da intervenção e de seus benefícios), humanização (aceitação social, psicológica e ética dos serviços, tendo em conta a satisfação dos usuários com a prestação do serviço) e equidade (igualdade na distribuição dos benefícios dos serviços de saúde entre indivíduos ou grupos).

De acordo com Matos, Pires e Campo (2009), para uma integração mais eficiente é recomendado a criação de um grupo de trabalho e que de acordo com a experiência no processo formativo, alguns aspectos devem ser levados em conta ao se constituir este grupo: o grupo de trabalho deve ser operativo, pois é importante levar em consideração aspectos práticos, como o número de pessoas que o irão constituir, a disponibilidade de tempo dessas pessoas e as facilidades logísticas para poder realizar reunião os de discussão entre seus integrantes. 
Ainda para os autores, em relação à seleção dos integrantes do grupo de trabalho, a experiência durante o processo formativo sugere que é recomendável que façam parte dele: profissionais com experiência nos programas a analisar os profissionais com capacidade de controle sobre tais programas. É recomendável, assim mesmo, incluir um facilitador no grupo ou estabelecer turnos de liderança entre os membros do grupo de trabalho.

A informação, por parte dos entrevistados, de que há boa comunicação entre as equipes do SAD e a Estratégia Saúde da Família é uma característica fundamental para a efetividade das ações pois, segundo Malagutti et al. (2012), fortalecer a comunicação entre os membros das equipes de saúde asseguram os seus empreendimentos e cumprimentos para a execução de práticas adequadas no tratamento domiciliar do paciente.

Portanto, é de vital importância que a relação de trabalho entre as equipes de ESF e do SAD, também sejam de cunho intersetorial, pois os cuidados aos pacientes com traqueostomia são complexos. Nota-se que já existem algumas iniciativas, em prol da melhoria da relação entre os programas, entretanto, as questões administrativas ligadas a admissibilidade do paciente no programa, parecem ser incipientes no que tange à responsabilidade de assumir ou não o usuário.

\section{Quarta Categoria: Avanços, limites e as perspectivas das equipes do Serviço de Atenção Domiciliar em relação a atuação em campo}

O modelo de atenção domiciliar à saúde, amplamente difundido no mundo, tem como alicerce o cliente, sua família, a composição domiciliar que engloba a equipe multiprofissional e o cuidador. No entanto, esse modelo ainda encontra-se em ascensão nas práticas de saúde, assim como no processo de formação e/ou capacitação dos profissionais de saúde (LACERDA et al., 2006).

Nessa categoria, os assuntos relacionados às potencialidades e fragilidades do serviço, são pontos vivenciados no cotidiano da equipe, conforme exemplos nos depoimentos.

\footnotetext{
"Eu vejo que o SAD é o serviço de extrema importância, a gente vê a resolutividade do programa, as condições que ele pode dar. É um programa excelente, quiçá pudesse ser um programa onde pudesse ser investido com mais intensificação na resolutividade desses problemas, que acabam travando o nosso serviço, mas é um serviço de excelência, e eu acredito muito. A estratégia saúde da família tem as suas limitações, o PACS tem as limitações também, e as equipes vão complementando
} 
entre si essas limitações e vão se adequando com essas falhas. O SAD, nós percebemos uma resolutividade um pouquinho mais acima". (P-9)

"O ponto positivo é da gente chegar na casa com uma equipe completa e ter a possibilidade de ajudar aquele paciente que, muitas vezes ele [a sua situação de saúde] vai ser dali pra pior. Então, a gente chega na casa do paciente, a gente vê a felicidade dele em receber a equipe. Então esse, eu acho, é o maior lado positivo, realmente: é o paciente ter uma equipe completa em casa. Imagina só quantas famílias têm esse benefício: pouquíssimas, que possa ter uma equipe de qualidade dentro de casa, e até desafogando o hospital. A gente atende e acaba atendendo também os parentes [do paciente]." (P-13)

"O ponto positivo que tem, assim, eu fico assim feliz ... com o cuidado que a gente tem com os pacientes né? A gente cuida com amor, a gente cuida com carinho e vai, faz nosso serviço, e isso é gratificante, tenho certeza que não só pra mim, mas para a equipe toda. A gente ta ali, com o paciente, acompanhando ele no dia-a-dia e vê e a evolução do paciente e a gente fica contente com isso." (P-10)

De modo geral, os entrevistados percebem o Programa de forma bastante positiva, considerando-o muito bom e de extrema importância para a saúde da população. De acordo com McEwn e Wills (2009) são muitas as vantagens e pontos positivos do Melhor em Casa, pois para os pacientes-usuários, lhes facilita se manter tão funcionais e independentes quanto possível, proporcionando uma melhor sensação de segurança e dignidade.

Concordando, Mosser e Begun (2015) afirmam que para as pessoas portadoras de doenças crônicas ou de incapacidade, ser tratado em casa, e não em um hospital, é, em geral, a melhor opção para o seu bem-estar físico e mental. É difícil quantificar as vantagens da companhia para alguém que necessita de cuidados em casa, porém sabe-se que o isolamento social pode causar sérios danos à saúde do indivíduo.

As percepções dos informantes também dão conta do alto nível de resolutividade do Programa Melhor em Casa, quando comparada à de outros programas assistenciais de saúde. De fato, quando relacionado à atenção tradicional, o Programa tem se posicionado como uma atenção que oferece serviços de saúde humanizados e oportunos à população, representando uma melhoria importante na qualidade de vida dos usuários e com um menor custo relativo. Além disso, no modelo de atenção domiciliar do Programa, cabem as atividades de todo o espectro dos serviços de saúde, desde o fomento e proteção da saúde, da atenção primária, da prevenção clínica, com o uso domiciliar de equipes tradicionalmente hospitalares.

A alta capacitação dos profissionais foi uma potencialidade do programa apontada na investigação. Essa característica é muito importante, pois de acordo com Giovanella et al. 
(2012), os profissionais de saúde qualificados, treinados e com os recursos necessários para a análise das necessidades de saúde podem garantir uma boa prestação de serviços.

As limitações das ações do Programa também são reconhecidas pelos informantes do estudo. Essas limitações têm relação, na sua essência, com a falta de estrutura das equipes, principalmente no que se referem a materiais e insumos, conforme já citado e discutido anteriormente. $\mathrm{Na}$ opinião de alguns profissionais, temos como fragilidades o seguinte:

Como fragilidade, é mais a questão de material de suporte, no caso específico, [...] por exemplo, bastão, terabante, faixa elástica, até mesmo os pesos, aparelho de aspiração, são equipamentos bem específicos, isso a gente não tem, mas eu sempre oriento o paciente, a gente monta, pega o cabo de vassoura, a gente adapta, sempre damos um jeitinho. (P-12).

"O SAD já existe há quatro anos, esfacelado durante todo esse tempo. Existe uma rotatividade muito grande de profissionais, mas eu vejo e acompanho a equipe e percebo assim que não há uma continuidade dos profissionais que já estão daqueles profissionais que iniciaram, onde houve todo um treinamento, pois a equipe do Ministério da Saúde veio para a implantação do serviço de atenção domiciliar no município de Macapá e fez a capacitação de todos os profissionais que iniciaram." (P-9)

"Eu, sinceramente, acho que isso [o programa] funcionaria muito mais se o governo investisse em melhorias nos postos.[...] Então aqui teria aspirador, teria equipamento de fisioterapia [...] Eu acho que você ir pra casa dos pacientes, você só ta dando, sinceramente, um alívio emocional, você não dá o alívio certo [...]. O nosso Programa é utopia, teoricamente é maravilhoso, mas não ajuda efetivamente as pessoas. Algumas a gente ajuda, por exemplo curativo; quem precisa de curativo, maravilha, fica em casa [...]' (P-3).

Em seu coletivo, os profissionais integrantes das equipes do Programa relataram um grande número de dificuldades enfrentadas. A principal delas se relaciona com a falta de material e equipamentos básicos, o que é uma deficiência muito grave, pois, segundo Mosser e Begun (2015), a dotação de falta de material e equipamentos básicos deverá ser adequada às funções que cada membro da equipe disciplinar realiza em seu labor domiciliar ao cliente, devendo compreender equipamentos e materiais de saúde adequados.

Para Giovanella et al. (2012), a falta de material e equipamentos para uma adequada intervenção domiciliar ocasiona atendimentos de qualidade inferior e pequena resolubilidade, o que acaba por implicar na produção de consultas de urgência dos pacientes mal atendidos, nas unidades de saúde. 
Além disso, esse é um cenário amplamente desfavorável à assistência dos usuários do Programa e fere a Portaria 963/2013 (BRASIL, MS, 2013, p. 3), a qual determina:

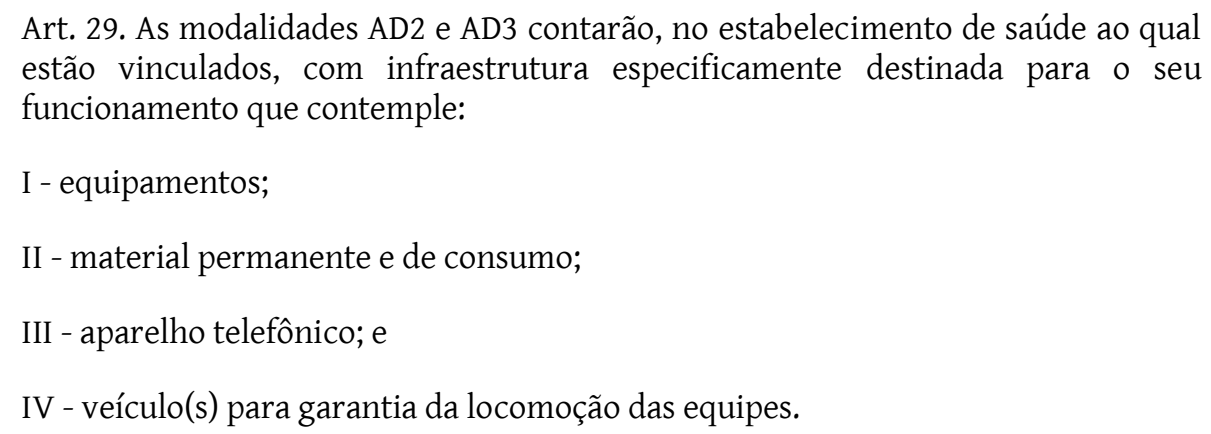

Percebe-se, através da fala dos informantes, que a dificuldade para se operacionalizar as ações do Programa, muitas vezes, é superada pela criatividade dos profissionais, que pode ser interpretado como um ponto positivo.

A criatividade pode ser entendida como o processo pelo qual um indivíduo ou um grupo, situado em uma determinada situação, elabora um produto novo ou original, adaptado às finalidades da situação (ALVES et al., 2011).

Esta capacidade pode ser desenvolvida por todas as pessoas e, em determinadas condições, os grupos podem favorecê-la. A esse respeito, Alves et al. (2011) indicam que as pessoas integrantes em grupos são capazes de assumir riscos, tomar decisões e propor ideias novas, que dificilmente fariam de maneira individual.

A esse mesmo respeito, Mosser e Begun (2015) assinalam que na tarefa de superar obstáculos ao longo de seu desempenho, os integrantes das equipes adquirem confiança e segurança na capacidade nos demais, reforçam as intenções de cada um para alcançar o objetivo da equipe.

A transição hospitalar de um paciente com traqueostomia para o domicílio é uma tarefa difícil, pela sua complexidade, tanto para os familiares como para as equipes multidisciplinares, pois esse processo engloba diversos obstáculos a ultrapassar (MARTINS, OLIVEIRA e SILVEIRA, 2011) 
Enfatiza-se, neste ponto, que pacientes portadores de doenças crônico-degenerativas possuem déficits funcionais, são dependentes de terceiros para a realização de atividades de vida diária e necessitam de cuidados no próprio domicílio, o que requer ainda a demanda por cuidados especializados prestados por equipes multiprofissionais de saúde (JORGE e JORGE, 2009)

Os pacientes que possuem cânulas de traqueostomia devem ser rotineiramente orientados quanto ao cuidado no domicílio, para a promoção da cicatrização do estoma, evitar infecção, manter a via aérea permeável e para dispor de conforto. Cabe à equipe multiprofissional, orientar o paciente e o cuidador quanto aos cuidados com o dispositivo, bem como o acompanhamento semanal aos mesmos.

0 exposto no estudo permite identificar que o trabalho em equipe constitui um ambiente propício para o desenvolvimento da criatividade. A existência do grupo propicia a exposição das ideias de cada um de seus membros. Nesse sentido, o grupo pode ser um espaço criativo, no qual todos estão dispostos a assumir coletivamente riscos e tomar decisões.

Conforme analisa Oliveira (2014), a ação ou atitude de um líder pode servir de incentivo para que a criatividade de um grupo aflore ou se iniba. Dar atenção às ideias e sugestões que procedem do pessoal, analisá-las com a equipe, melhorá-las e pô-las em prática contribui definitivamente para o desenvolvimento dos recursos humanos e para o melhoramento dos serviços de saúde.

A alta rotatividade do pessoal também é apontada pelos informantes como um problema recorrente, pois um profissional recém-chegado ao Programa carece, além de tomar conhecimento das políticas, ações e processos relativos a ele, se integrar ao grupo, a fim de dar sequência às atividades em andamento, o que, certamente, demanda tempo e esforço redobrado por parte de toda a equipe.

Entre as tantas percepções que podem ser colhidas das falas dos informantes, sem dúvida, uma das mais marcantes é o espírito de grupo e a dedicação de todos os membros das equipes. Saber trabalhar em equipe é, segundo Damázio e Gonçalves (2012), uma das condições, de trabalho de tipo psicológico, que mais influi nos trabalhadores de forma positiva, porque permite que haja companheirismo. Geralmente produz bons resultados, já que, normalmente, gera entusiasmo e produz satisfação nas tarefas programadas, que 
fomentam entre os trabalhadores um ambiente de harmonia em que se obtêm resultados benéficos. $O$ companheirismo se alcança quando existe trabalho e a amizade.

Giovanella et al. (2012) acrescentam que a força que integra a equipe e sua coesão se expressa na solidariedade e no sentido de pertinência à equipe, que seus componentes manifestam. Quanto mais coesão existe, mais provável é que a equipe compartilhe valores, atitudes e as normas de conduta comuns.

Mosser e Begun (2015) reforçam que o trabalho em equipe se torna proveitoso não somente para uma pessoa, mas para toda a equipe envolvida; para o grupo trará mais satisfação e tornará seus membros mais sociáveis; também ensinará o respeito às ideias dos demais e a necessidade de apoiar os colegas e que necessitam de ajuda.

Para Alves et al. (2011), uma equipe eficiente é formada por pessoas diferentes em ideias e tem interesses pessoais, porém, ao mesmo tempo, conscientes de que, ao pôr em comum seus conhecimentos e seus esforços, podem construir ideias novas e projetos novos que integram as ideias e os projetos individuais. Na medida em que essas ideias e esses projetos são transferidos à organização, o trabalho em equipe e favorece a mudança organizacional.

Outra fragilidade do Programa, percebido na fala de um dos informantes, tem relação com o seu caráter utópico, que não ajuda a população como deveria.

Apesar das conquistas e avanços do SUS, relacionados aos serviços e ações de saúde, e da ampliação da atenção básica por meio de programas como o ESF [e recentemente como o Programa Melhor em Casa], é perceptível que o modelo de atenção ainda é centrado na figura do hospital e no saber médico, com suas fragmentações, biologicismo e mecanicismo (BRASIL, MS, 2012).

É importante também avançar no que tange às novas formas de atuação e na modificação do cuidado fragmentado visto rotineiramente, em decorrência das desarmonias e das lacunas assistenciais existentes nos serviços, entre a oferta de serviços e as necessidades de saúde da população (SILVA, 2008; MENDES, 2011).

Espera-se enquanto atribuições da equipe, a realização de cuidados no domicílio, de uma maneira integral e resolutiva, firmados na factibilidade de ações voltadas não somente para a recuperação dos pacientes, mas principalmente no que diz respeito ao envolvimento com a comunidade. 
Diante de tudo o que foi exposto, considera-se que o objetivo geral da pesquisa foi atingido, ao identificar os conhecimentos, atitudes e práticas das equipes que compõe o Serviço de Atenção Domiciliar, em relação ao processo de atenção à saúde de pacientes com traqueostomia no município de Macapá, através do Programa Melhor em Casa.

\section{Quinta Categoria: Referência e contrarreferência no Programa Melhor em Casa diante das demandas ou problemas de saúde dos pacientes com traqueostomia}

Conceitua-se Sistema de Referência e Contrarreferência (RCR) como uma rede hierarquizada e integrada de cuidados e serviços que inicia na atenção primária e estende-se até aos serviços de alta complexidade e que proporciona o fluxo orientado dos pacientes nos dois sentidos (AGUIAR, 2001 citado por DIAS, 2010).

O SUS hierarquiza o sistema de saúde em três níveis de atenção: primário, secundário e terciário. Para que o acesso seja garantido nestes níveis de atenção é fundamental estabelecer um sistema de referência e contrarreferência, baseado na acessibilidade e continuidade da assistência.

Em se tratando de pacientes com traqueostomia e analisando os aspectos teóricos anteriormente citados, o estudo revelou a organização da referência e contrarreferência na interface com o SAD na rede de APS. No que concerne à admissão no Programa Melhor em Casa, do paciente com traqueostomia, tem-se os seguintes depoimentos:

[...] a maioria tem meu celular [risos], aí quando não vem referenciado pelo hospital nem pela unidade, pela Estratégia da Família, a família vem até nós, nessa sala, aí ela já vem com o endereço, nome do paciente e tudo pra gente fazer visita, a gente vai. Mas, muitas das vezes, é o diretor de posto que me liga, é algum enfermeiro das equipes de atenção da família, é psicólogo, é assistente social, aí a gente vai, faz a visita; dependendo do estado do paciente, a gente faz a admissão, porque a equipe atende pacientes acamados, só acamados, já a estratégia saúde da família atende a família toda" (P-11)

"Na admissão do paciente no SAD, o encaminhamento é feito através de uma ficha. O paciente sai de lá [do hospital] com uma guia de alta, nessa guia [...] o paciente sai com todos os diagnósticos, tempo de internação, o que foi que ele fez, quais os prognósticos, o que se deve fazer, quais as orientações que são dadas para o paciente pós-hospitalar. E aí em posse em posse dessa ficha, o EMAD já tem um parecer total [do paciente]. Faz-se o prontuário desse paciente e aí então nós vamos fazer a primeira visita dele. Se ele estiver realmente em condições de continuidade, aí a 
equipe absorve ele e faz a continuidade do tratamento até que ele esteja em condições de alta." (P-1)

“[...] normalmente, o hospital nem manda pro EMAD direto; ele manda de volta pra casa, pra marcar consulta no posto ou pra passar com o médico da família. É o PSF e o posto que encaminha pra gente. Mas eu acredito que o médico do próprio Pronto Socorro poderia encaminhar direto, é que falta comunicação, informação. Então vem, a família procura o posto mais próximo de casa e o posto ou PSF encaminha prá gente." (P-3).

A partir das falas dos entrevistados é possível perceber que existe uma desorganização dos fluxos de encaminhamentos dos pacientes com traqueostomia para as EMAD's, observase que o processo inicia na rede hospitalar, estende-se nas unidades básicas de saúde através das equipes de estratégia saúde da família, com interferência ainda das famílias dos pacientes para a condução dos trâmites de admissão no Programa Melhor em Casa. É destacada também pelos participantes do estudo, a existência de uma tramitação formal, na qual as fichas são adequadamente preenchidas conforme critérios estabelecidos nas diretrizes do Ministério da Saúde, entretanto, um ponto desfavorável é a tramitação informal que pode ser observada através das ligações para o celular de um dos profissionais, para tratar também de assuntos pertinentes à continuação do tratamento no domicílio, o que supostamente indica que as vias formais de acesso não funcionam adequadamente.

Quando este fluxo é realizado em sua mais alta eficiência atingimos o princípio da integralidade na sua plenitude. Porém, quando discursamos sobre hierarquia esses níveis de atenção tornam-se fragmentados, isolados e incomunicáveis, incapazes de prestar atenção contínua à população, em que a atenção primária não se comunica com a atenção secundária, consequentemente com a terciária. (BRASIL, 2015).

Outro ponto a ser destacado é em relação à organização para a realização dos exames complementares que são solicitados aos pacientes, marcação de consultas e procedimentos invasivos (troca de cânula de traqueostomia). Obtiveram-se os depoimentos:

[...] aqui no posto a gente tem um laboratório, que está funcionando, a equipe vai e faz a coleta na casa do paciente, urina, fezes e sangue, pega toda amostra do paciente e trás aqui para o posto. Agora com relação a USG, mamografia, raio X, exames mais complexos, a gente solicita a assistente social, pois ela tem um contato lá com o pessoal de HE, [...] o que ela consegue marcar, ela trás pra gente com as datas marcadas e entregamos ao paciente. Existe essa parceria. Isso foi evoluindo, não tinha essa ponte direta pra marcar os exames e as consultas, eles tentam melhorar cada vez mais, a gente teve uma evolução. P-12). 
Quando há necessidade de trocar a cânula de traqueostomia [...] é difícil. A gente tem que pedir pra passar com o cirurgião geral. Eu faço a solicitação e assistente social marca [para] o cirurgião, o paciente vai passar em consulta e aí depois é marcado o procedimento, no centro cirúrgico. 0 transporte [do paciente é feito na] ambulância [...]. Avisando com antecedência, a gente consegue a ambulância, da prefeitura $[. .].(\mathrm{P}-3)$

Constatou-se que algumas ações, como exames e marcação de consultas com o médico para a substituição de cânula de traqueostomia, por exemplo, são providenciadas previamente pela assistente social da equipe. Embora o baixo nível de regulação da rede resulte em dificuldades para o encaminhamento e agendamento de consultas e exames especializados dos pacientes inseridos no Programa Melhor em Casa, essa é uma constatação positiva, pois segundo Fonseca et al. (2011), as doenças crônicas e incapacitantes das quais, acredita-se que em geral, são acometidos os usuários do Programa, geram tanto no paciente como em seu cuidador e em toda sua família, alterações em seu estilo de vida, desgaste físico, dependência e repercussões sobre a área pessoal e social, o que torna mais difícil disponibilidade de tempo e meios necessários para, por exemplo, a busca de agendamento de consultas médicas e de outros procedimentos de saúde.

Mediante o exposto, parece que têm-se uma justificativa para a realização de exames no âmbito da atenção terciária, pois as solicitações, abordadas nos depoimentos, são providenciadas pela Assistente Social e os pacientes encaminhados ao Hospital de Clínicas Dr Alberto Lima ou para o Hospital de Emergência.

Embora os esforços coletivos de profissionais que atuam no SAD para os devidos ajustes com a atenção terciária, para conduzir a realização de consultas especializadas, exames (principalmente os de imagem) e procedimento invasivos, a situação mostra uma realidade distante do que é preconizado pelas normativas, o que torna um desafio para os gestores de saúde municipais no que tange ao aprimoramento e incorporação de recursos para a implantação de serviços laboratoriais e de apoio diagnóstico.

Nesse cenário também foi observado a organização e o desempenho das equipes no manejo das situações de urgência e emergência do paciente com traqueostomia. Os depoimentos revelam: 
As orientações que são repassadas a esse tipo de paciente quando apresenta déficit de oxigenação é para que a família acione o SAMU, pois esse paciente deverá ser encaminhado ao hospital de emergência e não para o hospital onde ele esteve internado anteriormente. A porta de entrada do serviço de atenção domiciliar é o hospital de emergência de Macapá, a logística é inicialmente emergencial, porém já tivemos pacientes oncológicos que entrou em necessidade de ser avaliado urgente e encaminhado, então entramos em contato com o Hospital de Clínicas Dr. Alberto Lima, pois existe um setor chamado clínica oncológica específico para atender este tipo de demanda. (P-9)

"A gente orienta a família que eles acionem a ambulância, porque o SAD, ele não trabalha aos finais de semana, e a gente não trabalha em regime de plantão também, a gente trabalha de segunda a sexta [feira] das $7 \mathrm{~h}$ às $12 \mathrm{~h}$. Então, qualquer alteração, qualquer emergência, a porta de entrada é o hospital de emergência." (P-6).

\footnotetext{
"Antigamente nós, por nossa conta, a gente fazia o atendimento no sábado e no domingo, por nossa conta. É regido pelo Programa, pelo Ministério [da Saúde], que haja o atendimento por escala [também no] sábado e domingo. Só que, no Amapá, nós não funcionamos assim, até por conta de estruturação, não funciona. Agora [na atualidade], a gente não pode mais fazer porque a nossa coordenação pediu que a gente parasse, por vários motivos, uma vez que a gente está indo no nosso carro, que o município [de Macapá] não tem a estruturação. Então, se houvesse algum problema [durante o atendimento domiciliar do cliente], nem se respaldar a gente podia. [...] Então, o que a gente orienta o paciente, desde o dia da admissão: Deu problema, ligue pro SAMU ou pros bombeiros, informe que é paciente assistido pelo SAD. Porque não que [o socorro] vai ter uma prioridade, mas vai haver uma preocupação dos profissionais de fora [da equipe], pra entender que ele [paciente] precisa de um atendimento mais urgente." (P-5).
}

Destaca-se, da fala dos informantes que o Programa Melhor em Casa não possui suporte (ambulância, atendimento em tempo integral, inclusive aos finais de semana e feriados, etc.) para o atendimento de situações de urgência e emergência dos seus usuários, tendo que lançar mão da estrutura do Serviço de Atendimento Móvel de Urgência (SAMU) nesses casos.

Tal constatação constitui um aspecto negativo do Programa, pois, segundo Assis et al. (2010), a proteção da saúde é de interesse público; portanto, é responsabilidade do Estado regulá-la e que o aperfeiçoamento da atenção que se proporciona durante o processo de transporte assistido do paciente em situações de urgência e emergência redunda, de maneira direta, na qualidade de vida de tais pacientes, ou quer torna de suma importância dotar todas as modalidades de atendimento de transporte adequado (ambulâncias), bem como de pessoal especializado.

Nas situações de urgência e emergência em que não há a necessidade de trasladar o paciente para unidades de atendimento, o estudo indica que tal atendimento é feito sempre em equipe, sobretudo se o paciente possui traqueostomia. Sobre essa questão, Fonseca et al. 
(2011) inserem que um fator de extraordinária importância na atenção à urgência e emergência é a disponibilidade de pessoal treinado e capacitado, o que garante uma atuação imediata de uma equipe multidisciplinar.

Apesar das inúmeras dificuldades, em especial a inexistência de uma rede poliárquica, pouco acesso garantido aos usuários, estrutura inadequada das UBS's, as equipes multiprofissionais de atenção domiciliar conseguem executar suas atividades com muita criatividade e comprometimento. Essa criatividade pode ser percebida através dos arranjos e improvisos que são realizados pelas equipes conforme as falas apresentadas no decorrer da dissertação.

Por fim, no que versa a respeito da alta do paciente no programa, destaca-se o depoimento de um participante, que relatou estratégias finais durante o processo da alta, conforme evidenciado no depoimento a seguir:

No caso, quando tem muito paciente prá nós [...] quando o paciente está estável, a gente dá alta e encaminha pro PSF; a gente tira daquela situação e encaminha pro PSF, com [...] tudo na fichinha. Aí o que é que a gente faz? A gente aciona a família [...] pra acionar o PSF, ou se não, eu vou lá com a coordenadora do SAD, aviso-a pra procurar a coordenadora do PSF pra ela entrar em contato [com as equipes] (P-4).

O depoimento evidencia a situação encontrada pelo profissional, com alto fluxo de pacientes internados no domicílio, na qual pode ser considerada prejudicial para os pacientes, além de ser, constrangedor para a equipe, em virtude das demandas e desafios a serem enfrentados ao repassar o caso para as equipes de ESF ou para a coordenação do Programa.

Embora para a alta domiciliar, seja necessário considerar a avaliação clínica e discutir o caso entre a equipe, é válido ressaltar que esta é realizada quando existe a melhora das condições clínicas e/ou estabilidade clínica, o quadro seja agravado e justifique a possibilidade de internação domiciliar, ocorra óbito do paciente ou que haja a inexistência de um cuidador para a autonomia no processo de cuidar. (BRASIL, 2012)

Com base nas premissas apresentadas, a equipe de atenção domiciliar se depara com um sistema de referência e contrarreferência desorganizado, com fragilidades na comunicação entre o SAD e as equipes de ESF. Para que as mudanças possam surgir é necessário o envolvimento de vários processos organizacionais, que inclui a estrutura 
operacional entre os níveis de atenção, a redefinição de papéis entre coordenadores e profissionais que atuam no domicílio.

\section{DISCUSSÕES}

Matta e Lima (2008) opinam que, de modo geral, para se chegar a estabelecer estratégias para melhoria da saúde pública, é necessário, em primeiro lugar, que os profissionais de saúde envolvidos possuam um marco teórico, legal e político sobre os programas de saúde por eles desenvolvidos, que ajude a orientar e a definir as ações dirigidas ao trabalho específico de cada um.

Um profissional sem conhecimento sobre o Programa, ou com um conhecimento fragmentado sobre ele, representa uma força de trabalho inadequada para a execução dos objetivos do Melhor em Casa. Assim, como aponta Sarreta (2009), a falta de pessoal adequado para atender as exigências do serviço de saúde, decorrente da falta de treinamento e capacitação específica, implica na ausência de competências profissionais para enfrentar tais desafios.

Com relação ao processo de trabalho, um traço característico bem marcante da atividade de planejamento diário dos profissionais é que todos participam dele, com ideias. Isso pode ser considerado muito relevante ao levar-se em consideração o que acham Moyses Filho et al. (2010) do planejamento, um processo orientado à ação por meio do qual uma instituição se adapta às mudanças tanto em sua estrutura interna como no seu ambiente exterior. Assim, o processo de planejamento requer um cálculo atualizado da realidade cambiante, pelo que seu caráter grupal é imprescindível.

Ao abordar-se as tecnologias utilizadas pelas equipes do SAD, primeiramente é importante reconhecer que a falta de equipamentos básicos para o atendimento dos pacientes parece ser a característica mais marcante, apresentada pelo estudo. E esse é um dado negativo, pois muitos procedimentos em saúde prescindem de determinados insumos, equipamentos e tecnologias. 
Ao se tratar das concepções sobre o serviço e a relação de trabalho com a estratégia saúde da família, percebeu-se, a partir das falas dos informantes, que as tímidas medidas de integração do SAD e a Estratégia Saúde da Família foram de iniciativa dos membros das equipes domiciliares, em razão das dificuldades para a oferta de um serviço mais ágil ao paciente, e não por iniciativa das coordenações dos programas.

Assis et al. (2010) julgam ser importante a integração dos serviços entre programas, tanto para os prestadores da atenção da saúde como para os pacientes. As políticas para a integração dos serviços deveriam incluir aspectos da integração clínica (relacionados com os benefícios para os pacientes) e aspectos organizativos (relacionados com a melhoria das condições de trabalho para os profissionais da atenção da saúde).

Sobre os avanços, limites e as perspectivas das equipes do SAD em relação à atuação em campo, de modo geral, os entrevistados percebem o Programa de forma bastante positiva, considerando-o muito bom e de extrema importância para a saúde da população. De acordo com McEwn e Wills (2009) são muitas as vantagens e pontos positivos do Melhor em Casa, pois para os pacientes-usuários, lhes facilita se manter tão funcionais e independentes quanto possível, proporcionando uma melhor sensação de segurança e dignidade.

Giovanella et al. (2012) também defendem as vantagens de um programa de atenção domiciliar. Para os autores, essa modalidade de atendimento de saúde altera em um grau mínimo o modo de vida do paciente. Como ele permanece em sua residência, não perde o controle do lar e não precisa separar-se de seus entes queridos, estando livre das normas e restrições hospitalares. Também se altera em grau mínimo a vida diária dos seus familiares. Isso é particularmente importante nos pacientes com enfermidades em estágios terminais e doenças crônicas não transmissíveis, que habitualmente requerem internações hospitalares por longos períodos de tempo.

Outra fragilidade do Programa, percebido na fala de um dos informantes, tem relação com o seu caráter utópico, que não ajuda a população como deveria. Apesar das conquistas e avanços do SUS, relacionados aos serviços e ações de saúde, e da ampliação da atenção básica por meio de programas como o ESF [e recentemente como o Programa Melhor em Casa], é perceptível que o modelo de atenção ainda é centrado na figura do hospital e no saber médico, com suas fragmentações, biologicismo e mecanicismo (BRASIL, MS, 2012). 
Em relação ao sistema de referência e contrarreferência no Programa Melhor em Casa diante das demandas ou problemas de saúde dos pacientes com traqueostomia, com base nas premissas apresentadas, a equipe de atenção domiciliar se depara com um sistema de referência e contrarreferência desorganizado, com fragilidades na comunicação entre o SAD e as equipes de ESF. Para que as mudanças possam surgir é necessário o envolvimento de vários processos organizacionais, que inclui a estrutura operacional entre os níveis de atenção, a redefinição de papéis entre coordenadores e profissionais que atuam no domicílio.

\section{CONSIDERAÇÕES FINAIS}

As concepções dos profissionais de saúde participantes do estudo, com relação ao Programa Melhor em Casa, demonstraram fragilidades quanto à diversos aspectos em relação ao conhecimento do modo de ver as ações que são levadas às casas dos usuários do Programa.

O conhecimento fragmentado de alguns agentes talvez decorra de dois fatores principais: o pouco tempo em que tais profissionais foram integrados às equipes do Programa e o nível de experiências em atendimentos domiciliares. Porque estando há pouco tempo atuando no Programa pode ser um elemento limitante do conhecimento teórico acerca dos objetivos, métodos e práticas inerentes a ele, do mesmo modo que, quanto mais presentes forem as experiências vividas no âmbito dele, quantitativamente e qualitativamente, mais amplos serão os conhecimentos práticos dos profissionais envolvidos. É possível, também, que essa falta de experiência prática no Programa justifique a crença relacionada com a inviabilidade das ações dele.

Observou-se ainda que a estrutura disponível para a realização da atenção domiciliar é um ponto crítico e desfavorável comparado ao arcabouço teórico que o programa preconiza.

O estudo demonstrou, também, que as equipes multidisciplinares do Programa têm o cuidado de planejar suas atividades, o que é o almejado para qualquer ação em saúde. No entanto, nessas ações de planejamento, não se percebeu a participação social, embora no Brasil, a sociedade esteja organizada de maneira tal que torne factível sua participação nos diferentes setores e grupos de população, na proposição de soluções dos problemas particulares, incluindo os da saúde. É possível que existam fatores que obstaculizem a 
participação social, nesse caso particular, e eles devem ser investigados e avaliados, a fim de serem neutralizados como fontes de oponentes do processo.

Nesse contexto, deve-se priorizar e incentivar a realização de práticas voltadas ao atendimento domiciliar, que favoreça ambos os lados: o essencial, que é a assistência integral ao indivíduo internado no domicilio, assim como as equipes multiprofissionais que precisam de suporte estratégico para o alcance e a execução de suas atividades em campo.

Outra preocupação dos profissionais percebida nesta investigação foi a realização periódica de estudos de casos clínicos. Sem dúvida isso denota o zelo pela implementação de ações voltadas para a formação contínua do profissional de saúde, considerando-se os avanços e aperfeiçoamentos que ocorrem, constantemente, nas técnicas e procedimentos técnicos nas várias áreas que compõem o Programa.

Por outro lado, ficou evidente a ausência de conhecimento sobre a classificação quanto aos tipos de tecnologias para o uso das equipes. Os profissionais consideram apenas a utilização de tecnologias duras, tais como, materiais, equipamentos e insumos necessários para os procedimentos técnicos e operacionais, evidenciando o desconhecimento das demais tecnologias, entre elas, a comunicação verbal com os pacientes como um meio de tecnologia.

Dessa forma, o aspecto relacionado ao estabelecimento do vínculo, que vai muito além do uso de aparatos tecnológicos, estabelecido através da escuta e a comunicação, pode ser um fator a ser repensado e organizado pelas equipes que atuam no SAD municipal, para que o processo do cuidado seja de fato bem sucedido.

Nessa conjuntura, outro ponto destacado diz respeito a única ambulância que o Programa possui, para o transporte de pacientes de casa para atendimentos fora de seu domicílio, por exemplo, além de ser insuficiente para cobrir toda a demanda, constantemente é levada à manutenção, deixando este serviço descoberto e, consequentemente, prejudicando a qualidade do atendimento prestado à população. Essa é apenas uma das diversas dificuldades enfrentadas pelas equipes. Falta de aparelho para a aspiração de pacientes com traqueostomia até insumos básicos para a realização de curativos. Algumas dessas dificuldades são superadas, ou ao menos amenizadas com dedicação e criatividade por parte dos profissionais. 
Também foi possível considerar o Melhor em Casa como um programa tronco, conectado com os demais programas assistenciais existentes dentro da oferta de serviços da atenção primária de saúde. É de vital importância que a relação de trabalho entre as equipes de ESF e do SAD, também sejam de cunho intersetorial, pois os cuidados aos pacientes com traqueostomia são complexos. Nota-se que já existem algumas iniciativas, em prol da melhoria da relação entre os programas, entretanto, as questões administrativas ligadas a admissibilidade do paciente no programa, parecem ser incipientes no que tange à responsabilidade de assumir ou não o usuário.

Nesse sentido, o trabalho em equipes multidisciplinares de saúde deve ser considerado como uma modalidade dentro de uma gama de práticas colaborativas. Importa reconhecer os benefícios que essa modalidade proporciona, não somente aos pacientes, mas também aos membros da equipe. Convém que, periodicamente, a equipe se concentre não apenas nas tarefas específicas, mas que também dedique tempo para questionar-se "como estamos trabalhando juntos?" e "em que áreas necessitamos de treinamento para melhorar nossa efetividade?".

Percebeu-se a essência do conceito de equipe de saúde, em que todos os membros que a integram trabalham em colaboração com o usuário, com sua família e com sua comunidade, que consigam um esforço harmônico que contribua para o objetivo de melhorar as condições de saúde das pessoas.

Embora fora possível perceber que existe uma desorganização dos fluxos de encaminhamentos dos pacientes com traqueostomia para as EMAD's, observa-se que o processo inicia na rede hospitalar, estende-se nas unidades básicas de saúde através das equipes de estratégia saúde da família, com interferência ainda das famílias dos pacientes para a condução dos trâmites de admissão no Programa Melhor em Casa. Foi destacada no estudo, a existência de uma tramitação formal e informal, o que supostamente indica que as vias formais de acesso não funcionam adequadamente.

É possível concluir que o modelo de assistência que se propõe o Programa Melhor em Casa se coloca a favor de uma de assistência integral ao indivíduo, sendo de extrema importância a disponibilização de condições mínimas necessárias para a execução das práticas que ultrapassem o modelo tradicional de assistência à saúde. 
No entanto, a escassez de profissionais, aliada à falta de equipamentos, transportes, materiais e insumos, acaba inviabilizando, em parte, as práticas de trabalho, tornando o sistema de saúde defasado, sobrecarregando os macro-componentes dos níveis de média e alta complexidade em saúde.

Apesar das inúmeras dificuldades, em especial a inexistência de uma rede poliárquica, pouco acesso garantido aos usuários, estrutura inadequada das UBS's, as equipes multiprofissionais de atenção domiciliar conseguem executar suas atividades com muita criatividade e comprometimento.

Após apresentarmos reflexões e contribuições para a possível implementação de melhorias para o serviço de atenção domiciliar no município de Macapá, - especialmente aos pacientes com traqueostomia - sugerimos algumas medidas que poderão ser de grande valia nesse processo.

- Reforço da qualificação dos profissionais das EMAD/EMAP's acerca das diretrizes e normativas do Programa Melhor em Casa, pois estas precisam ser ancoradas em saberes técnicos, científicos e legais.

- Estruturação da RAS e oferecer suporte estratégico entre os níveis de atenção, para a realização da atenção domiciliar, para o alcance e a execução de atividades em campo.

- Proporcionar espaço para a elaboração de um planejamento participativo para a realização de troca de experiências e estudos de casos, inserindo a opinião do paciente ou familiar no planejamento da assistência à saúde.

- Avaliação do dimensionamento das equipes do SAD, a fim de diminuir a sobrecarga de atividades para os membros da equipe, considerado pelos entrevistados como um fator limitador, podendo haver interferência nos cuidados prestados ao indivíduo, comprometendo a sua qualidade de vida.

- Promoção de maior diálogo entre as equipes de ESF e SAD, pois os cuidados aos pacientes com traqueostomia são complexos e necessitam de um acompanhamento com maior frequência semanal. 
- Organização do sistema de Referência e contrarreferência para atendimento aos pacientes com traqueostomia.

Pelo que foi apresentado, acredita-se que, este estudo contribuiu no sentido de apontar as condições de trabalho e os principais problemas e desafios existentes no Programa Melhor em Casa no município de Macapá, com relação ao atendimento do paciente com traqueostomia, na tentativa de estimular a elaboração de novas investigações que visem o aperfeiçoamento do atendimento domiciliar de saúde.

\section{REFERÊNCIAS}

AGUIAR, José Manuel Monteiro. O Programa Saúde da Família no Brasil: a resolutividade do PSF no Município de Volta Redonda (RJ). [tese de doutorado]. Rio de Janeiro: Escola Nacional de Saúde Pública, Fundação Oswaldo Cruz, 2001.

ALVES, R.F. org. Psicologia da saúde: teoria, intervenção e pesquisa [online]. Campina Grande: EDUEPB, 2011. $345 \mathrm{p}$.

AMAPÁ (estado). Secretaria de Estado da Saúde. Resolução n.. 015/12 - CIB/AP, dispõe sobre a aprovação do projeto de implantação do Serviço de Atenção Domiciliar (SAD) no município de Macapá. Macapá (AP), 2012. Acesso em 15 abr. 2016. Disponível em https://saude.portal.ap.gov.br/conteudo/institucional/comissaointergestores-bipartite

ASSIS, Marluce Maria Araújo (Org.). Produção do cuidado no Programa Saúde da Família: olhares analisadores em diferentes cenários. Salvador: EDUFBA, 2010.

BARDIN, Laurence. Análise de Conteúdo. Lisboa. Edições 70. 2009.

BRASIL. Ministério da Saúde. Secretaria de Atenção à Saúde. Departamento de Atenção Básica. Caderno de atenção domiciliar / Ministério da Saúde, Secretaria de Atenção à Saúde, Departamento de Atenção Básica. Brasília: Ministério da Saúde, 2012. 2 v.: il.

BRASIL. Lei 10.424, de 15 de abril de 2002. Acrescenta capítulo à Lei 8080, de 19 de setembro de 1990, que dispõe sobre as condições para a promoção, proteção, recuperação da saúde, a organização e funcionamento de serviços correspondentes e dá outras providências, regulamentando a assistência domiciliar no Sistema Único de Saúde. Brasília (DF): Diário Oficial da República Federativa do Brasil; 16 abr 2002. P.1

BRASIL. Portaria № 2.029, de 24 de agosto de 2011 (Revogada pela PRT GM/MS № 2.527 de 27.10.2011) Institui a Atenção Domiciliar no âmbito do Sistema Único de Saúde (SUS). Disponível em: http://bvsms.saude.gov.br/bvs/saudelegis/gm/2011/prt2029_24_08_2011.html. Acesso em 25 mai. 2016

. Ministério da Saúde. Portaria № 963 de 27 de maio de 2013 - Redefine a Atenção Domiciliar no âmbito do Sistema Único de Saúde (SUS). Diário Oficial da União. Brasília, DF. 2013.

. Ministério da Saúde. Portaria № 1.208 de 18 de junho de 2013 - dispõe sobre a integração do Programa Melhor em Casa (atenção domiciliar no âmbito do SUS) com o Programa SOS Emergências, 
ambos inseridos na rede de atenção às urgências. Diário Oficial da União. Brasília, DF. 2013. Disponível em shttp://bvsms.saude.gov.br/bvs/saudelegis/gm/2013/prt1208_18_06_2013.html>. Acesso em 04 abr. 2015

. Ministério da Saúde. Portaria no 825, de 25 de abril de 2016.

Redefine a Atenção Domiciliar no âmbito do Sistema Único de Saúde (SUS) e atualiza as equipes habilitadas. Diário Oficial da União. Brasília, DF. 2016. Disponível em $<$ http://www.saude.sp.gov.br/ses/legislacao/informe-eletronico-de-legislacao-em-saude/acessar-osinformes-eletronicos/2016/abril/informe-eletronico-de-legislacao-em-saude-n-7526042016?br.com.mmcafe.mmpublish.core.entity.Folder\%20:\%20PERFIL\%20-\%20id:\%2081>. Acesso em $30 \mathrm{abr}$. 2016

Conselho Nacional de Saúde. Resolução 466 de 12 de dezembro de 2012. Dispõe sobre as diretrizes e normas regulamentadoras de pesquisas envolvendo seres humanos. Brasília, DF. 2012

Ministério da Saúde. Departamento de Atenção Básica. Teto, Credenciamento e Implantação das estratégias de Agentes Comunitários de Saúde, Saúde da Família e Saúde Bucal. 2015. Disponível em: $<$ HTTP://dab.saude.gov.br/dab/historico_cobertura_sf/historico_cobertura_sfrelatoriophp>. Acesso em 01 jun. 2015

COSTA, A.M. Integralidade na Atenção e no Cuidado à Saúde. In: Saúde e Sociedade. Vol. 13, n 3, set-dez. 2004

DAMÁZIO, Luciana; GONÇALVES, Carlos Alberto. Desafios da gestão estratégica em serviços de saúde. Rio de Janeiro, 2012.

DIAS, Camila Ferreira. o Sistema de Referência e Contrarreferência na Estratégia Saúde da Família no Município de Bauru: Perspectivas dos Gestores. Botucatu, 2010 Dissertação (mestrado) - Faculdade de Medicina de Botucatu, Universidade Estadual Paulista, 2010. Disponível em:

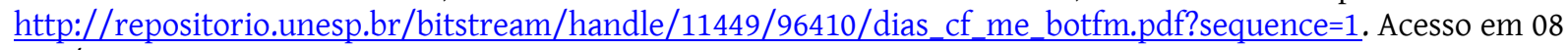
mai/2016.

ECHER, Isabel Cristina; FENGLER, Fernanda; FINARD, Simone; GLAESER, Sheila; GUNTZEL, Adriana Meira; MARTINS, Frederico Krieger; NUNES, Diego Silva Leite; SEVERO, Isis Marques. Manual de Orientações sobre Traqueostomia. s.n [sine nomine]. Porto Alegre. 2013. V.19. Disponível em: $<$ https://www.hcpa.ufrgs.br/downloads/Comunicacao/19_traqueostomia_montado.pdf>. Acesso em 15 nov/2014.

FONSECA, Ariadne da Silva; PETERLINE, Fábio Luís; CARDOSO, Maria Lúcia Alves Pereira; LOPES, Luciene Lourenço Abbate; DIEGUES, Sylvia Regina Suelotto. Enfermagem de emergência. Rio de Janeiro: Elsevier, 2011.

GIL, A.C. Métodos e técnicas de pesquisa social. 6 ed. São Paulo, Altas, 2008.

GIOVANELLA, Lígia; ESCOREL, Sarah; LOBATO, Lenaura de Vasconcelos Costa; NORONHA, José Carvalho de; CARVALHO, Antônio Ivo de; Políticas e sistemas de saúde no Brasil. 2 ed. Rio de Janeiro: Fiocruz, 2012.

Gomes ELR, Anselmi ML, Mishima SM, Villa TCS, Pinto IC, Almeida MCP. Dimensão histórica da gênese e incorporação do saber administrativo na enfermagem. In: Almeida MCP, Rocha SMN, organizadoras. $O$ trabalho de enfermagem. São Paulo (SP): Cortez; 1997. p. 229-50.

JORGE, Eliza Sophia Delbon Atiê. JORGE, Márcia Delbon. Assistência domiciliária. In: RAMOS, Dalton Luiz de Paula. Bioética Pessoa e Vida. São Caetano do Sul, SP: Difusão, 2009.

LACERDA, Maria Ribeiro. GIACOMOZZI, Clélia Mozara. OLINISKI, Samantha Reikdal. TRUPPEL, Thiago Christel. Atenção à Saúde no Domicílio: modalidades que fundamentam sua prática. Revista Saúde e Sociedade v.15, n.2, p.88-95, maio-ago 2006.

MACAPÁ. Secretaria Municipal de Saúde. Plano Municipal de Saúde 2014 - 2017. Macapá: PMM, 2014. 
MALAGUTTI, William (Org.). Assistência domiciliar: atividades da assistência em enfermagem. Rio de Janeiro: Rubio, 2012.

MARX, Karl. Os Economistas, O Capital, Crítica da Economia Política. Vol. I. Livro Primeiro. O Processo de Produção do Capital. (Prefácios e Capítulos I a XII). Editora Nova Cultural Ltda. 1996, Círculo do Livro Ltda.

MARQUES, G.Q, LIMA MADS. As tecnologias leves como orientadoras dos processos de trabalho em serviços de saúde. Rev Gaúcha Enferm [Internet]. 2004 Abr [cited 2013 Apr 25]; 25(1):17-25. Available from: http://www.lume.ufrgs.br/bitstream/handle/10183/23537/000439821.pdf?sequence=1

MARTINS, Helena. OLIVEIRA, Isabel Salvado de. SILVEIRA, Teresa. A criança com traqueostomia e a sua família face à alta clínica. Artigo de revisão de literatura. Revista de Ciências da Saúde da Escola Superior de Saúde da Cruz Vermelha Portuguesa, Vol. 3, Março 2011. Disponível em <http://www.salutisscientia.esscvp.eu/Site/download.aspx?artigoid=30555>. Acesso em 09 Mai/2015.

MATTA, Gustavo Corrêa; LIMA, Júlio César França. Estado, sociedade e formação profissional em saúde: contradições e desafios em 20 anos de SUS. Rio de Janeiro: Fiocruz, 2008.

MATHEUS, Mariana Queiroz; LEITE, Silvana Maria Coelho; DÁZIO, Eliza Maria Rezende. Compartilhando o Cuidado da Pessoa Ostomizada. In: Congresso Brasileiro de Extensão Universitária 2.2004. Belo Horizonte. Anais eletrônicos. Belo Horizonte: UFMG. Disponível em <https://www.ufmg.br/congrext/Saude/Saude57.pdf>. Acesso em 15 out/2014.

MATOS, Eliane; PIRES, Denise Elvira Pires de; CAMPOS, Gastão Wagner de Sousa. Relações de trabalho em equipes interdisciplinares: contribuições para a constituição de novas formas de organização do trabalho em saúde. In Rev. Bras. de Enfermagem. Nov-dez, 2009, 62. Brasília: 2009.

McEWEN, Melanie; WILLS, Evelyn M. Bases teóricas de Enfermagem. 4 ed. Porto Alegre: Artmed, 2009.

MENDES, Eugênio Vilaça. As Redes de Atenção à Saúde. Brasília: Organização Pan-Americana da Saúde, 2011.

MENDES, Eugênio Vilaça. A Construção Social da Atenção Primária à Saúde. Brasília: Conselho Nacional de Secretários de Saúde - CONASS, 2015. 193 p.: il.

MENDES-GONÇALVES, R. B. Tecnologia e Organização Social das Práticas de Saúde: Características Tecnológicas do Processo de Trabalho na Rede Estadual de Centros de Saúde de São Paulo. São Paulo: Editora Hucitec/ABRASCO, 1994.

MERHY, E. Saúde: a cartografia do trabalho vivo. 3 ed. São Paulo: Hucitec, 2002.

MERHY E.E, FEUERWERKER, L.C.M. Novo olhar sobre as tecnologias de saúde: uma necessidade contemporânea. [online]. [cited 2013 July 31]. Available from: http://www.uff.br/saudecoletiva/professores/merhy/capitulos-25.pdf

MOYSÉS FILHO, Jamil (Org.). Planejamento e gestão estratégia em organizações de saúde. Rio de Janeiro: FGV, 2010.

MOSSER, Gordon; BEGUN, James W. Comprendendo o trabalho em equipe na saúde. Porto Alegre: Artmed, 2015.

OLIVEIRA, Silvério da Costa. Criatividade, inovação e controle nas organizações de trabalho. 2 ed. Rio de Janeiro: [s.n.]. 2014.

RICZ, H.M.A.; et al.. Traqueostomia. Medicina, Ribeirão Preto, v.44, n.1, p. 63-69, 2011. Disponível em: <http://www.fmrp.usp.br/revista/2011/vol44n1/Simp7_Traqueostomia.pdf> Acesso em: 27 dez/2014

SANNA, Maria Cristina. Os processos de trabalho em enfermagem. Rev. Bras. Enf. v. 62, n. 2, p. 221-224, mar/abr. 2007. 
SANTOS, Flavia Pedro dos Anjos. Processo de Trabalho das Equipes de Saúde da Família na Produção do Cuidado aos Usuários com Hipertensão Arterial. 2010. 169 f. Dissertação (Mestrado em Enfermagem e Saúde) - Universidade Estadual do Sudoeste da Bahia, Jequié - BA. Disponível em: <http://www.uesb.br/ppgenfsaude/dissertacoes/turma1/Disserta\%C3\%A7\%C3\%A3o\%20Flavia\%20P.\%20dos\%2 0\%20A.\%20Santos.pdf>. Acesso em 04.06.15

SARRETA, Fernanda de Oliveira. Educação permanente em saúde para os trabalhadores do SUS. São Paulo: Cultura Acadêmica, 2009.

SCOTTINI, Alfredo. Minidicionário escolar da língua portuguesa. Blumenau, SC: Todolivro Editora, 2009.

SILVA, Silvio Fernandes da (Org.). Redes de Atenção à Saúde no SUS: o pacto pela saúde e redes regionalizadas de ações e serviços de saúde. Campinas: IDISA, 2008. Revista Ciência e Saúde Coletiva, 16 (6):2753-2762

SMELTZER, S.C; BARE, B.G. Brunner \& Suddarth. Tratado de Enfermagem Médico-cirúrgica. 10 ed. Rio de Janeiro (RJ): Guanabara Koogan, 2005.

\section{(cc) Br}

Este trabalho está licenciado com uma Licença Creative Commons - Atribuição 4.0 Internacional. 